\title{
Proficiency Testing Scheme for Pesticides in Honey
}

\author{
Elvire Messineo, Emeline Dioré, Nicolas Le Baron and Abdelkader Boubetra \\ Interprofessional Bureau of Analytical Studies (BIPEA), 189 Rue d'Aubervilliers, Paris 75018, France
}

\begin{abstract}
Agricultural contamination with pesticides is a challenging problem for both human and bee health. Consequently, a number of laboratories performing pesticides residues analyse in honey and honey products has gradually increased in recent years. In the framework of their accreditations according to ISO 17025 standard, these laboratories must control their performances through interlaboratory comparison. Interprofessional Bureau of Analytical Studies (BIPEA) organizes regular proficiency testing schemes (PTS) in many analytical domains, including the analysis of pesticides in honey, to compare the performances of the laboratories. As an example, one test was conducted in October 2015 using an organic honey spiked with 21 pesticides, at levels between $15 \mu \mathrm{g} / \mathrm{kg}$ and $200 \mu \mathrm{g} / \mathrm{kg}$, with 27 participating laboratories. This test was intended for the identification and quantification of 21 molecules of pesticides residues. The techniques used by the laboratories were GC-MS-MS, LC-MS-MS, GC-MS and GC-ECD, according to the molecules. Participating laboratories were required to return their results on a dedicated website after a period of one month, and a statistical treatment of the data was performed according to ISO 13528 standard. Assigned (consensus) values were calculated from the participants' results and the performances of the laboratories could then be evaluated individually and collectively according to ISO 17043 standard. The results of this test were satisfactory for detection and quantification, whatever the analytical technique. The molecules were correctly identified by the laboratories and the recovery rates ranged from $56 \%$ up to $88 \%$. The dispersions of the results, studied through the coefficients of variation, were also satisfactory ranging from $7 \%$ to $30 \%$. This test showed that the laboratories participating routinely in this kind of tests are very competent in the analysis of pesticides residues in honey. It also allowed the participating laboratories to draw up a general inventory of their analytical skills, and it was a very useful tool to detect bias or non-compliant results. It acted as a warning signal for the implementation of corrective and/or curative actions in the laboratories.
\end{abstract}

Key words: Proficiency testing schemes, pesticides, honey, quality control, laboratory performance.

\section{Introduction}

The generalised use of pesticides in modern agriculture widely impacts the honey production, with consequences for human health due to the consumption of contaminated products with various pesticides residues and the exposure of manufacturers or applicators [1]. Similarly, those pesticides are involved with health disease for bees, which were described in several papers [2-5]. In the framework of their accreditations according to ISO 17025 standard [6], laboratories must participate in interlaboratory comparison to control their performances and compare their results to the ones of other laboratories. Interprofessional Bureau of Analytical Studies (BIPEA) organizes regular proficiency testing

Corresponding author: Elvire Messineo, M.Sc., research field: interlaboratory comparison. schemes (PTS) in many analytical domains, including the analysis of pesticides in honey and honey products.

The PTS organized by BIPEA allows laboratories to check their performance and represents a tool for quality management, permitting them to control the accuracy and trueness of their results and to quantify the bias and the drift of them. They act as a warning signal for the implementation of corrective and/or curative actions [7].

The pesticides in honey PTS was created in 2010, and up to now four tests per year have been organized. The example described below concerns samples proposed in October 2015, with 27 participating laboratories. This test was intended for the analysis of the content of pesticides, by determination of 21 molecules, either by gas chromatography with mass spectrometry (GC-MS) or tandem mass spectrometry 
(GC-MS-MS) or electron capture detector (GC-ECD), or by high performance liquid chromatography with mass spectrometry detection (LC-MS), according to the molecules $[8,9]$.

\section{Methodology}

\subsection{Production and Shipment of the Samples}

The raw material chosen for the test was collected from the market in Paris, France. A single batch was used. It should be liquid at room temperature to facilitate the homogenization step, thus an acacia honey was selected for this test. This honey should be organic product, to limit its pesticides contents. The batch chosen for the test was first check for its absence of pesticides by Capinov, an accredited subcontracting laboratory working with BIPEA.

Once this batch accepted, the honey was mixed in a dedicated container, and then spiked with a mix containing 21 pesticides at levels from $15 \mu \mathrm{g} / \mathrm{kg}$ to $200 \mu \mathrm{g} / \mathrm{kg}$. After mixing, the product was sampled using an automatic piston system, which distributed the products in successive layers into flasks that were being positioned on a belt conveyor. This system involved the quasi simultaneous filling of the samples and ensured also the homogeneity between all the samples.

The samples were frozen at $-24 \pm 6{ }^{\circ} \mathrm{C}$ immediately after their distribution, to avoid any degradation of the pesticides due to the rise in temperature.

In order to verify this production, a homogeneity check was conducted on 10 samples taken from the production at regular intervals. The determination in duplicate of boscalid parameter was conducted by Capinov, an accredited subcontracting laboratory working with BIPEA, in random order. Several statistical tests (Fisher test, Cochran test, test of significant inhomogeneity) were conducted according to ISO 13528 standard, in order to confirm that the samples were homogeneous enough to meet the requirements of this proficiency test.

The samples were then dispatched at the end of
September 2015 to the laboratories, in refrigerated packaged parcels with express couriers, to be received by the participants within a period of the maximum four days according to the destination.

There are altogether 27 laboratories registered for this PTS, ranging from France (seven laboratories), Italy (five), Germany (four), Spain (three), the Netherlands (two), Canada (one), United Arab Emirates (one), Macedonia (one), New Zealand (one), United Kingdom (one) to Uruguay (one).

\subsection{Collection of the Results and Statistical Treatment of the Data}

Participating laboratories were required to return their results on a dedicated website within a period of one month. They had to fill in an online reply form, defining the parameters to be determined, their units and the number of significant digits, the methods to be used and the analysis conditions, using a confidential login and passwords to enter and transmit their results. Before any statistical treatment, the whole traceability of the procedure, from the sample production to the results of each participant was then checked. Among the participants, 22 sent back some results to BIPEA.

A statistical treatment of the data was performed according to ISO 13528 standard [10].

Assigned values $(X)$ [11] were calculated from the participants' results for each parameter, using the robust mean of the results included in the interval (90\% of the spiking value $\pm 40 \%$ ). This selection fostered the results with high recovery rates. Moreover, the use of robust statistics as this iterative process minimized the influence of the most extreme values.

The tolerance value (VT) applied to each analyte was a fraction of the assigned value and was defined as follows: if $X \leq 0.100 \mathrm{mg} / \mathrm{kg}, V T=50 \%$ of the assigned value; if $X>0.100 \mathrm{mg} / \mathrm{kg}, V T=40 \%$ of the assigned value $+0.010 \mathrm{mg} / \mathrm{kg}$.

The results could then be evaluated as regards this tolerance value, and the performances of the laboratories could be evaluated individually and 
collectively according to ISO 17043 [12], using $Z$-scores [13]. They are expressed in terms of standard deviation from their means. The formula used to calculate $z$-scores is given as Eq. (1):

$$
Z=\frac{X-x}{\frac{V T}{2}}
$$

where, $X=$ assigned value of the analytical parameter, $x=$ result of the laboratory, $V T / 2=$ half the tolerance value applied for the analytical parameter.

\subsection{Interpretation of the Data}

The Z-scores can be classified as the following: If $|Z| \leq 2$, the result is "satisfactory"; If $2<|Z| \leq 3$, the result is "questionable"; If $3<|Z|$, the result is "unsatisfactory".

A Z-score is calculated for each result, and the laboratories can then classify their results and implement some corrective and/or curative actions if necessary.

\section{Results and Discussion}

The recovery rates for each parameter and the coefficients of variation of each molecule are given in Table 1. Except for acrinathrin, which level is very low, the recovery rates were satisfactory (from $56 \%$ to $88 \%$ ). Coefficients of variation, reflecting the dispersion of the results as a function of the contamination level, were also satisfactory for this test, ranging from $7 \%$ to $30 \%$ according to the molecule. This shows a good consistency of the results from one laboratory to another, whatever the technique.

Assigned values, spiking values and the percentage of out of tolerances results for each analytical parameter are given in Fig. 1. The highest rate of out of tolerance results was obtained for carbendazime and

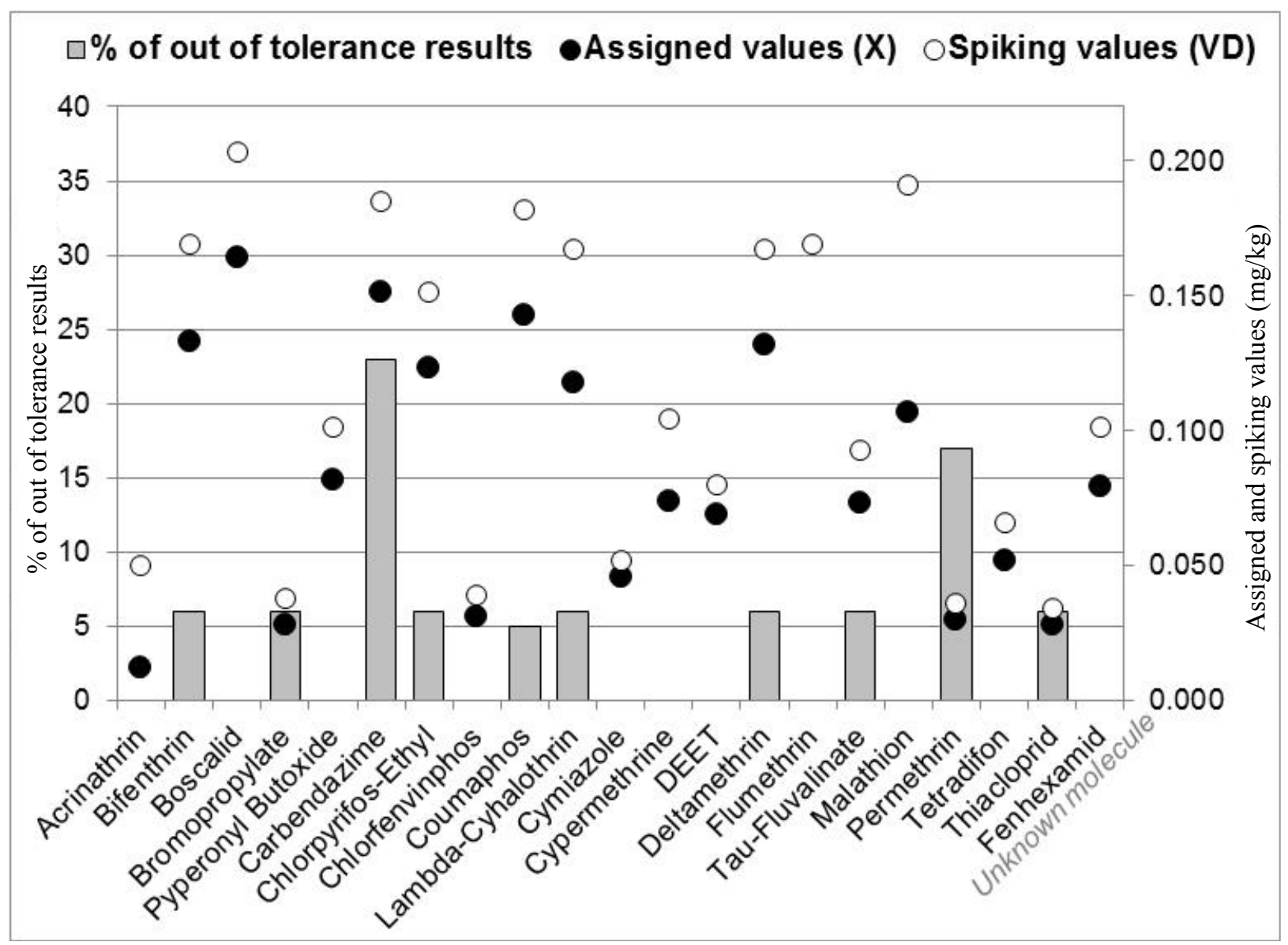

Fig. 1 Out of tolerance results per parameter, assigned and spiking values for all the spiked molecules. 
Table 1 Recovery rates and coefficients of variation of the spiked molecules.

\begin{tabular}{lllll}
\hline Molecules & $\begin{array}{l}\text { Spiking value } \\
(\mathrm{mg} / \mathrm{kg})\end{array}$ & $\begin{array}{l}\text { Assigned value } \\
(\mathrm{mg} / \mathrm{kg})\end{array}$ & $\begin{array}{l}\text { Recovery rate } \\
(\%)\end{array}$ & Coefficient of variation $(\%)$ \\
\hline Acrinathrin & 0.050 & 0.012 & 24 & 25 \\
Bifenthrin & 0.169 & 0.133 & 79 & 17 \\
Boscalid & 0.203 & 0.164 & 81 & 12 \\
Brompropylate & 0.038 & 0.028 & 74 & 18 \\
Pyperonil butoxide & 0.101 & 0.082 & 81 & 12 \\
Carbendazime & 0.185 & 0.151 & 82 & 25 \\
Chlorfenvinphos & 0.039 & 0.031 & 79 & 23 \\
Chlorpyrifos-ethyl & 0.151 & 0.123 & 81 & 18 \\
Coumaphos & 0.182 & 0.143 & 79 & 26 \\
Lambda-cyhalothrin & 0.167 & 0.118 & 71 & 20 \\
Cymiazole & 0.052 & 0.046 & 88 & 30 \\
Cypermethrin & 0.104 & 0.074 & 71 & 23 \\
Deltametrine & 0.167 & 0.132 & 79 & 17 \\
DEET (diethyltoluamide) & 0.080 & 0.069 & 86 & - \\
Flumethrine & 0.169 & - & - & 7 \\
Malathion & 0.191 & 0.107 & 56 & 23 \\
Permethrine & 0.036 & 0.030 & 84 & 25 \\
Tau-Fluvalinate & 0.093 & 0.073 & 78 & 17 \\
Tetradifon & 0.066 & 0.052 & 79 & 18 \\
Thiacloprid & 0.034 & 0.028 & 83 & 22 \\
Fenhexamid & 0.101 & 0.079 & 78 & \\
(blind molecule) & & & & \\
\hline
\end{tabular}

Table 2 Overview of the results given by the laboratories.

\begin{tabular}{|c|c|c|c|c|c|c|c|}
\hline Lab ID & $\begin{array}{l}\text { No. of } \\
\text { molecules to be } \\
\text { determined }\end{array}$ & $\begin{array}{l}\text { No. of results } \\
\text { given by the lab }\end{array}$ & $\begin{array}{l}\text { No. of no } \\
\text { quantitative } \\
\text { results }\end{array}$ & $\begin{array}{l}\text { No. of under- } \\
\text { estimated } \\
\text { results }\end{array}$ & $\begin{array}{l}\text { No. of over- } \\
\text { estimated } \\
\text { results }\end{array}$ & $\begin{array}{l}\text { No. of out of } \\
\text { tolerance } \\
\text { results }\end{array}$ & $\begin{array}{l}\text { Percentage of out } \\
\text { of tolerance results } \\
(\%)\end{array}$ \\
\hline 1005 & 21 & 5 & & & & 0 & 0 \\
\hline 1075 & 21 & 20 & 1 & & & 0 & 0 \\
\hline 1503 & 21 & 10 & & & & 0 & 0 \\
\hline 1657 & 21 & 1 & & & & 0 & 0 \\
\hline 1686 & 21 & 11 & & & & 0 & 0 \\
\hline 1893 & 21 & 19 & & & & 0 & 0 \\
\hline 3076 & 21 & 20 & & & & 0 & 0 \\
\hline 3455 & 21 & 9 & & & & 0 & 0 \\
\hline 3625 & 21 & 11 & & & & 0 & 0 \\
\hline 4043 & 21 & 19 & 1 & & & 0 & 0 \\
\hline 4110 & 21 & 17 & & & & 0 & 0 \\
\hline 5157 & 21 & 17 & & & & 0 & 0 \\
\hline 5281 & 21 & 8 & & & & 0 & 0 \\
\hline 5391 & 21 & 5 & & & & 0 & 0 \\
\hline 5461 & 21 & 21 & & & & 0 & 0 \\
\hline 4422 & 21 & 19 & & 1 & & 1 & 5 \\
\hline 2862 & 21 & 16 & & & 1 & 1 & 6 \\
\hline 4302 & 21 & 16 & & & 1 & 1 & 6 \\
\hline 5936 & 21 & 16 & & 1 & & 1 & 6 \\
\hline 3867 & 21 & 12 & & & 1 & 1 & 8 \\
\hline 1517 & 21 & 9 & & 1 & 1 & 2 & 22 \\
\hline 1281 & 21 & 19 & & & 7 & 7 & 37 \\
\hline
\end{tabular}




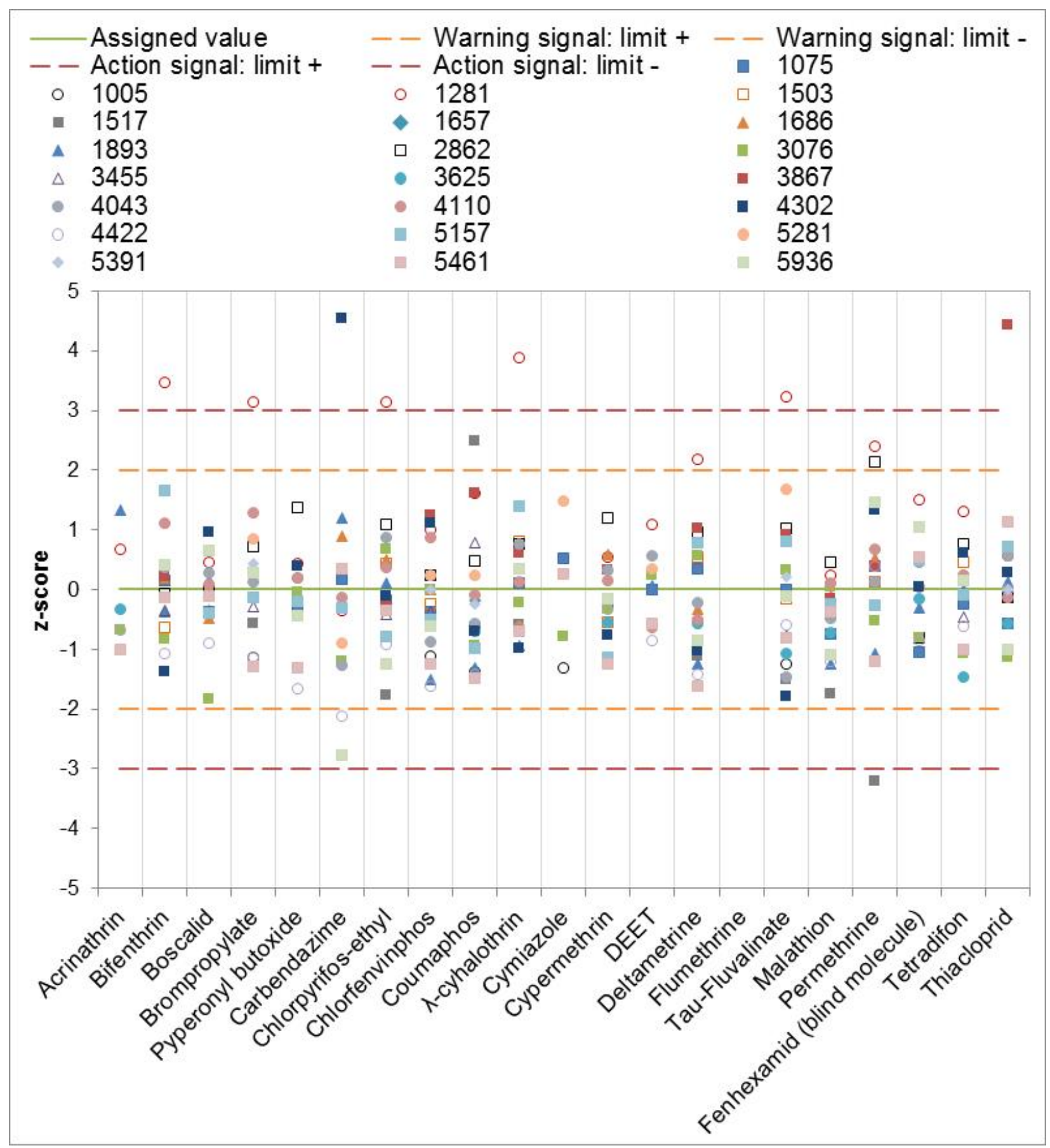

Fig. 2 Overview of $Z$-scores by molecule in all laboratories.

was probably due to interferences with other compound of honey. Indeed, this analysis is less specific in multi-residue screening, which increases the dispersion of the results. It was not possible to estimate an assigned value for flumethrin due to the too low number of results received. The results were satisfactory for most of the laboratories and for most of the analytical parameters, as the ratio of out of tolerance results was most of less or equal to $6 \%$ (which corresponds to only one laboratory).

The unknown molecule, fenhexamid, was identified and quantified by 13 laboratories. No false negative nor false positive results were received, which shows the good control of this kind of routine analysis in the 
laboratories.

The percentage of out of tolerance results compared to the number of results sent back by each laboratory is given in Table 2. Most of the laboratories are below $10 \%$ of out of tolerance results, which shows that the laboratories are experienced and familiar with those analyses.

This test allowed also BIPEA to draw up a general inventory of the performances of the laboratories, using Z-scores: some warning signals $(Z$-score $=|2|)$ or action signal $(Z$-score $=|3|)$ can be used to evaluate the results of the laboratories (Fig. 2).

The results are very satisfactory for this test, as most of the laboratories obtained Z-scores $<|2|$. Some further comments can be made from this overview. It can be seen that one laboratory has a positive bias for many molecules (Lab 1281); only seven laboratories (Lab 1281, 1517, 2862, 3867, 4302, 4422 and 5936) had out of tolerance results, and among them, only four (1281, 1517, 3867 and 4302) had unsatisfactory results with $Z$-scores $>|3|$ for one or several molecules. All the other laboratories had good results, which show that those laboratories, accredited according to ISO 17025 for most of them, are really competent and qualified to conduct analyses of pesticides in honey and honey products.

\section{Conclusions}

The results of these tests were satisfactory for most of the molecules and the major part of the laboratories. It shows that those laboratories, accredited according to ISO 17025 for most of them, are really competent and qualified to conduct analyses of pesticides in honey and honey products. These tests enable the participating laboratories to draw up a general inventory of their analytical skills.

This kind of test is very useful to detect bias or non-compliant results and thus act as a warning signal for the implementation of corrective and/or curative actions in the laboratories.

Participation in several proficiency tests per year is of considerable importance, particularly to detect drift or bias in the results, through the use of control charts.

Proficiency tests are an essential tool for the quality management of laboratories and for the continuous improvement of their analytical performance.

\section{References}

[1] Maroni, M., and Fait, A. 1993. "Health Effect in Man from Long-Term Exposure to Pesticides: A Review of the 1975-1991 Literature." Toxicology 78 (1-3): 1-180.

[2] Chauzat, M. P., Carpentier, P., Martel, A. C., Bougeard, S., Cougoule, N., Porta, P., Lachaize, J., Madec, F., Aubert, M., and Faucon, J. P. 2009. "Influence of Pesticide Residues on Honey Bee (Hymenoptera: Apidae) Colony Health in France." Environ Entomol. 38 (3): 514-23.

[3] Blasco, C., Fernández, M., Pena, A., Lino, C., Silveira, M. I., Font, G., and Picó, Y. 2003. "Assessment of Pesticide Residues in Honey Samples from Portugal and Spain.” J. Agric. Food Chem. 51 (27): 8132-8.

[4] Mukherjee, I. 2009. "Determination of Pesticide Residues in Honey Samples." Bull Environ. Contam. Toxicol. 83 (6): 818-21.

[5] Al-Waili, N., Salom, K., Al-Ghamdi, A., and Ansari, M. J. 2012. "Antibiotic, Pesticide, and Microbial Contaminants of Honey: Human Health Hazards." The Scientific World Journal. doi: 10.1100/2012/930849.

[6] International Organization for Standardization (ISO). 2005. "General Requirements for the Competence of Testing and Calibration Laboratories." ISO/IEC 17025:2005. Accessed May, 2005. https://www.iso.org/obp/ui/\#!iso:std:39883:en.

[7] Shakhashiro, A., and Mabit, L. 2009. "Results of an IAEA Inter-comparison Exercise to Assess ${ }^{137} \mathrm{Cs}$ and Total ${ }^{210} \mathrm{~Pb}$ Analytical Performance in Soil.” Applied Radiation and Isotopes 67 (1): 139-46.

[8] Rissato, S. R., Galhiane, M. S., De Almeida, M. V., Gerenutti, M., and Apon, B. M. 2007. "Multi-residue Determination of Pesticides in Honey Samples by Gas Chromatography-Mass Spectrometry and Application in Environmental Contamination." Food Chemistry 101 (4): 1719-26.

[9] Pang, G. F., Fan, C. L., Liu, Y. M., Cao, Y. Z., Zhang, J. J., Fu, B. L., Li, X. M., Li, Z. Y., and Wu, Y. P. 2007. "Multi-residue Method for the Determination of 450 Pesticide Residues in Honey, Fruit Juice and Wine by Double-Cartridge Solid-Phase Extraction/Gas Chromatography-Mass Spectrometry and Liquid Chromatography-Tandem Mass Spectrometry." Food Additives and Contaminants 23 (8): 777-810. 
[10] International Organization for Standardization (ISO). 2015. "Statistical Methods for Use in Proficiency Testing by Interlaboratory Comparisons." ISO 13528:2015. Accessed August,

2005. https://www.iso.org/obp/ui/\#iso:std:iso:13528:ed-2:v2:en.

[11] Koch, M., and Metzgu, J. W. 2001. "Definition of Assigned Values for Proficiency Tests in Water Analysis." Accreditation and Quality Assurance 6 (4): 181-5.

[12] International Organization for Standardization (ISO).
2010. "Conformity Assessment-General Requirements for Proficiency Testing." ISO/IEC 17043:2010. Accessed February,

2010. https://www.iso.org/obp/ui/\#!iso:std:29366:en.

[13] Veenendaal, H. R., Van Berkel, P. M., De Jong, G., and Baggelaar, P. K. 2007. "A New Approach in Accessing Microbiological Results in Water Analyses Proficiency Testing." Accreditation and Quality Assurance 12 (7): 365-9. 